\title{
The Spatial Distribution of Apis Dorsata Host Plants Using an Integrated Geographical Information System-Remote Sensing Approach
}

\author{
${ }^{1}$ Izzat F. Ibrahim, ${ }^{1}$ Siva K. Balasundram, ${ }^{2}$ Nur-Ashikin P. Abdullah, \\ ${ }^{3}$ Alias M. Sood, ${ }^{1}$ Makhdzir Mardan and ${ }^{4}$ Mohamed M. Saberioon \\ ${ }^{1}$ Department of Agriculture Technology, Faculty of Agriculture, \\ ${ }^{2}$ Department of Crop Science, Faculty of Agriculture, \\ ${ }^{3}$ Department of Forest Production, Faculty of Forestry, \\ ${ }^{4}$ Department of Civil Engineering, Faculty of Engineering, \\ Universiti Putra Malaysia, 43400 Serdang, Selangor, Malaysia
}

Received 2012-05-21, Revised 2012-09-06; Accepted 2012-09-20

\begin{abstract}
Apis dorsata is one of the important honeybee species in tropical and subtropical regions that forages on various plants including herbs, grasses, forest trees and plantation trees. However, information on the spatial distribution of various pollen sources of Apis dorsata is still lacking. This study aimed at mapping the spatial distribution of the major honeybee plants that serve as pollen sources to Apis dorsata using an integrated Geographical Information System (GIS)-Remote Sensing (RS) approach. Mapping of pollen sources was based on SPOT-5 satellite imagery within a GIS environment. The SPOT-5 imagery was enhanced, classified and vectorized using ENVI 4.7. Image classification techniques were used to separate the pollen sources into six classes. Ten observation plots, each measuring $10 \times 10 \mathrm{~m}$, were established for each pollen source class using a randomized sampling technique. Results showed that Melaleuca cajuputi covered a total of 2,398.8 ha (5.5\%), Acacia sp. 11,377.8 ha (25.9\%), Elaeis guineensis 19745.1 ha (44.9\%), non-vegetation 4,647.2 ha (10.6\%), water bodies 973.5 ha (2.2\%) and cloud/haze/shadow 4830.5 ha $(10.6 \%)$. The overall classification accuracy was $91.5 \%$ and the Kappa coefficient was 0.8 . The GIS-RS map showed that almost all of the Apis dorsata nesting sites were located in the Elaeis guineensis area. This study clearly demonstrates that Apis dorsata prefers to build its nest in close proximity to the pollen source.
\end{abstract}

Keywords: Apis Dorsata, Geographical Information System, Remote Sensing, Honeybee Plant

\section{INTRODUCTION}

More often than not, only certain plant species have been shown to be important for honeybee foraging. Some of these plant species supply both nectar and pollen abundantly when in bloom and they are often called honeybee plants. Plants that produce nectar but little or no pollen are typically termed as honey plants, while plants that yield pollen but little or no nectar are typically termed as pollen plants. These pollen plants are important especially at the time of colony build-up, when the bees need large amounts of protein for their broodrearing. There are some plant species that are specifically important to Apis dorsata. These species can be found in the wild and as cultivated plants. They include wood trees (Melaleuca cajuputi, Acacia sp.), fruit trees (Mangifera indica, Durio zibethinus), industrial crops (Elaeis guineensis, Hevea brasiliensis, Cocos nucifera) and weeds (Asystsia intrusa, Mimosa pudica).

Manual mapping methods to measure and develop inventories on vegetation coverage within a diverse ecosystem that usually attracts honeybee foraging such

Corresponding Author: Siva K. Balasundram, Department of Agriculture Technology, Faculty of Agriculture, Universiti Putra Malaysia, 43400 Serdang, Selangor, Malaysia 
as a tropical rainforest is time-consuming and costly. Geo-spatial tools such as Geographic Information System (GIS) and Remote Sensing (RS) offer a relatively cheaper means of surveying and mapping vegetation distribution over large areas.

Few studies have been conducted on the utility of RS technology for management of Apis sp. In Spain, Mezquida and Martinez (2009) monitored beehives of Apis mellifera based on the colony buzz registered by acoustic sensors that transmit data signals to a common database. They established a platform to store real-time information about the swarm's daily activity. Jo et al. (2001) used Landsat satellite imagery and GIS to analyze the habitation of Acacia sp. as a honey plant in Young-chon, Korea. In Malaysia, Saberioon et al. (2009) used SPOT-5 satellite imagery to inventory and produce a vegetation map of Melaleuca sp., which is a source of nectar and pollen for Apis dorsata. Sulzer et al. (2010) used RS platforms to detect relevant information about Apis dorsata swarms, which typically migrate to the southern sub-tropical part of Nepal.

In Malaysia, the type of honey/pollen plants favorable to Apis dorsata is well documented. However, there is little information on the spatial distribution of these plants, especially in Marang, Terengganu where honey hunting is an important economic activity among rural dwellers. Honey hunting generates high returns because the price of honey is high, ranging from USD5 $\mathrm{kg}^{-1}$ to USD7 $\mathrm{kg}^{-1}$ during peak season. The conservation of natural forest that comprises plant species important for the sustenance of Apis dorsata is a priority in Terengganu, a state that has been declared as Malaysia's honey hub.

Information about the distribution of plant species that serve as a source of pollen and/or nectar for Apis dorsata colonies in Marang, Terengganu is critical. Combining information about the spatial distribution of vegetation, Apis dorsata colonies and their nesting behaviour will make it feasible to predict and locate Apis dorsata nesting sites. Hence, the objective of this study was to map the spatial distribution of three major honey/pollen sources, which are Melaleuca cajuputi, Acacia sp. and Elaeis guineensis, using an integrated GIS-RS approach.

\section{MATERIALS AND METHODS}

\subsection{Study Site}

This study was conducted in Marang district, located in the state of Terengganu at the north eastern part of Peninsular Malaysia (Fig. 1) between an upper left of $5^{\circ}$ $21^{\prime} \mathrm{N}, 102^{\circ} 58^{\prime} \mathrm{E}$ and a lower left of $4^{\circ} 49^{\prime} \mathrm{N}, 102^{\circ} 51^{\prime} \mathrm{E}$ with a total areal coverage of 43972 ha.

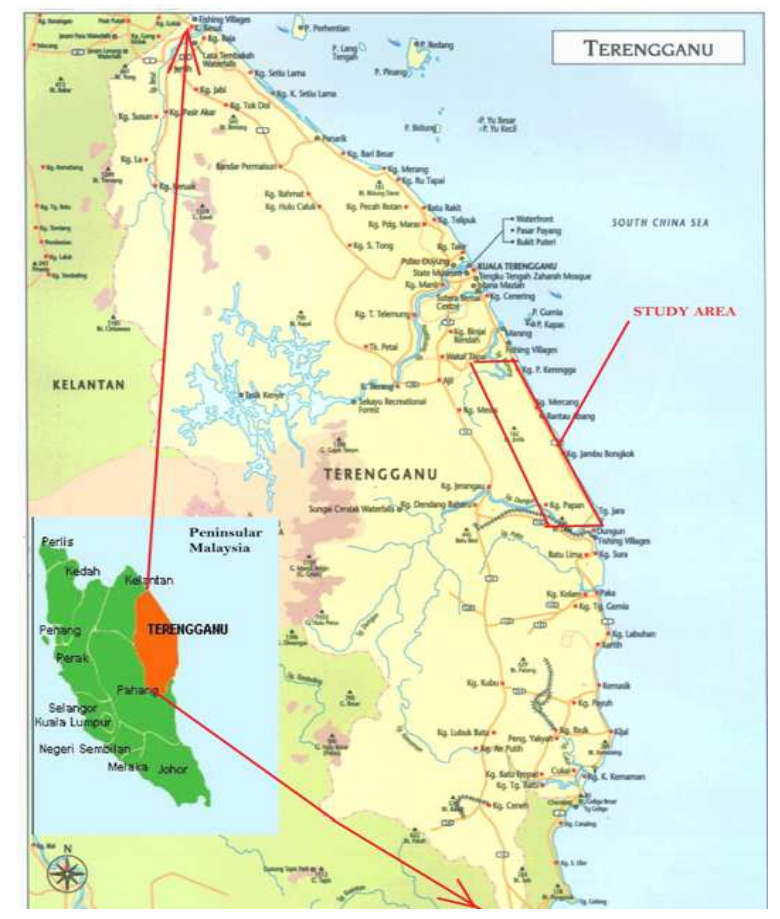

Fig. 1. Location of study area 
Table 1. SPOT-5 image specifications

\begin{tabular}{ll}
\hline Tear & 2009 \\
\hline Date of Acquisition & September 19, 2009 \\
Georeferencing & Modified Everest-RSO (by MACRES) \\
Pixel Depth & Unsigned 8-bit \\
Pixel Size & $10 \times 10 \mathrm{~m}$ \\
Band & B1:0.50-0.59 $\mu \mathrm{m} / \mathrm{Green}$ \\
Wavelength/ & B2:0.61-0.68 $\mu \mathrm{m} /$ Red \\
Resolution & B3:0.79-0.89 $\mu \mathrm{m} /$ Near Infra Red (NIR) \\
& B4:1.58-1.75 $\mu \mathrm{m} /$ Middle Infra Red (MIR) \\
Band type & Red, Green, NIR and MIR \\
\hline
\end{tabular}

\subsection{Satellite Imagery}

SPOT-5 with $10 \mathrm{~m}$ resolution in multispectral mode was used to produce a land cover map. The SPOT-5 imagery, captured on September 19, 2009, was obtained from the Malaysian Center for Remote Sensing (MACRES). Digital image analysis was performed using ENVI 4.7, an image processing program. Details of the SPOT-5 imagery are given in Table 1 .

\subsection{Band Combination}

Bandwidths corresponding to visible green, visible red and Near Infra Red (NIR) were combined to generate a standard False Color Composite (FCC) image. The FCC format is gives the best result in visual interpretation and digital image processing for land cover classification (Mohti, 2006).

\subsection{Image Classification}

Image classification is aimed at assigning pixels within the image a particular class or theme. In this study, six classes were delineated based on the study objectives. The classes were: (i) Elaeis guineensis, (ii) Acacia sp., (iii) Melaleuca cajuputi, (iv) Water bodies, (v) Non-vegetation and (vi) Cloud/Haze/Shadow. To map the study area into six classes, Maximum Likelihood Classification (MLC) algorithm was applied into different supervised classification schemes.

\subsection{Accuracy Assessment}

Confusion Matrix (CM) was used to quantify the accuracy of a classification outcome by comparing the classified pixels to ground truth observation. Overall accuracy and Kappa coefficient were also calculated. The overall accuracy was calculated by summing the number of pixels classified correctly and dividing them by the total number of pixels (Hudson and Ramm, 1987). The ground truthed Region of Interest (ROI) define the true class of pixels. The pixels classified correctly are found along the diagonal of the confusion matrix table which lists the number of pixels that match the correct ground truth class. The total number of pixels represent the sum of all pixels in all the ground truth classes. The Kappa coefficient is another measure of classification accuracy, which quantifies the agreement between classified image and reference image. The Kappa coefficient tests the overall agreement for each matrix based on the difference between the actual agreement of the classification (i.e., with regard to the reference data) and the chance agreement.

\subsection{Field Survey}

Acquisition of ground data for this study was conducted on January of 2011. In situ data were collected for twenty nine sites. Among these, twelve sites were dominated by Elaeis guineensis (Oil palm), eight sites had Acacia sp. (Acacia) and nine sites had Melaleuca cajuputi (Gelam) as the major vegetation. Allocation of sampling locations was based on a stratified random procedure (Toan et al., 2004). Plots measuring $10 \times 10 \mathrm{~m}$ each was registered on the satellite image using a Global Positioning System (GPS). Sampling locations were geo-referenced using a handheld Garmin 76CS with an accuracy of $15 \mathrm{~m}$.

Location of nesting sites of Apis dorsata colonies were also geo-referenced using Garmin 76CS. All coordinate data of latitudes and longitudes (WGS84) were converted to Malaysian Rectified Skew Orthomorphic (RSO) using ArcGIS 9.3.1.

\subsection{Spatial Map}

The distribution of Elaeis guineensis, Acacia sp. and Melaleuca cajuputi from the classified SPOT-5 imagery was converted from raster to vector and transferred into ArcGIS 9.3.1. Three other spatial layers were integrated, which are: (i) distribution of Apis dorsata nesting sites, (ii) access paths such as roads and rivers (derived from digital cartographic maps at 1:25000 scale) and (iii) foraging range (marked as a $1-\mathrm{km}$ radius from the nesting site using the buffer function in ArcGIS 9.3.1).

\section{RESULTS}

Ground truthing was carried out to determine reference points for supervised classification. These reference points were used in the mapping of Melaleuca cajuputi (Gelam), Acacia sp. (Acacia) and Elaeis guineensis (Oil palm) distribution. 


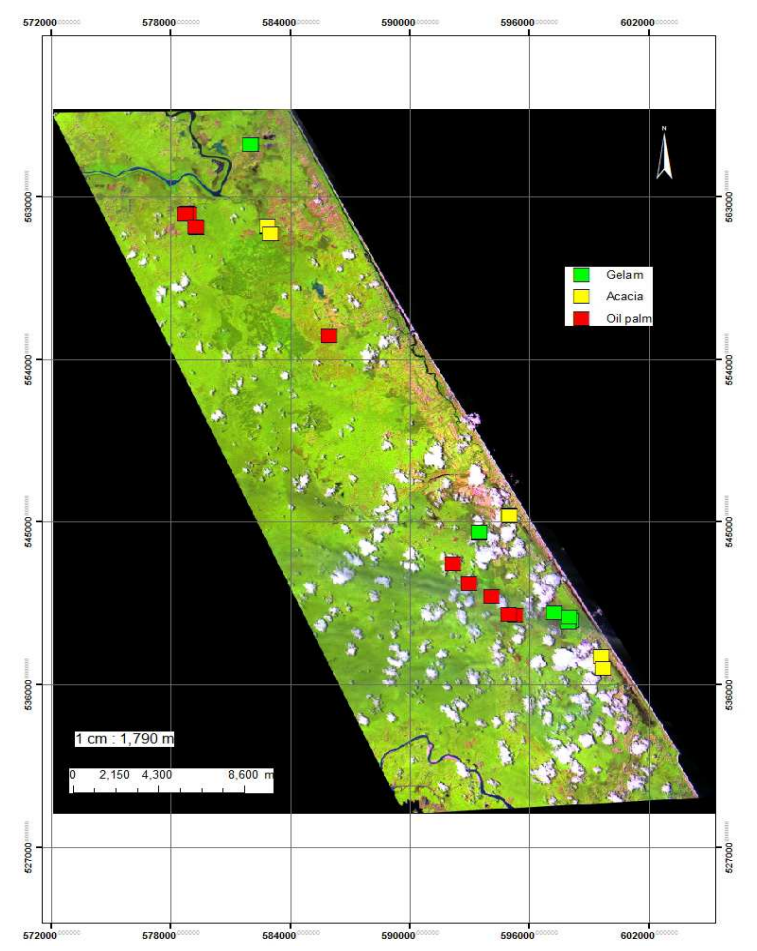

Fig. 2. Location of training sites

Table 2. Geographical coordinates of ground truthing points

\begin{tabular}{llll}
\hline No & East & North & Type \\
\hline 1 & 595334 & 539856 & Oil palm \\
2 & 594973 & 539902 & Oil palm \\
3 & 594111 & 540927 & Oil palm \\
4 & 593007 & 541629 & Oil palm \\
5 & 592175 & 542696 & Oil palm \\
6 & 585981 & 555357 & Oil palm \\
7 & 585945 & 555344 & Oil palm \\
8 & 578872 & 562136 & Oil palm \\
9 & 578929 & 562062 & Oil palm \\
10 & 578763 & 562085 & Oil palm \\
11 & 579302 & 561340 & Oil palm \\
12 & 579256 & 561374 & Oil palm \\
13 & 599638 & 537610 & Acacia \\
14 & 599737 & 536919 & Acacia \\
15 & 594968 & 545434 & Acacia \\
16 & 595013 & 545388 & Acacia \\
17 & 582903 & 561388 & Acacia \\
18 & 582894 & 561398 & Acacia \\
19 & 583093 & 560981 & Acacia \\
20 & 583031 & 560989 & Acacia \\
21 & 598088 & 539609 & Gelam \\
22 & 598015 & 539486 & Gelam \\
23 & 597987 & 539495 & Gelam \\
24 & 598009 & 539799 & Gelam \\
25 & 597252 & 540034 & Gelam \\
26 & 593495 & 544415 & Gelam \\
27 & 593524 & 544491 & Gelam \\
28 & 582089 & 565907 & Gelam \\
29 & 582043 & 565896 & Gelam \\
\hline & & &
\end{tabular}

Table 3. Classes generated on the SPOT-5 image based on MLC algorithm

\begin{tabular}{lll}
\hline Class code & Description & Color \\
\hline 1 & Elaeis guineensis (Oil palm) & Red \\
2 & Acacia sp. (Acacia) & Blue \\
3 & Melaleuca cajuputi (Gelam) & Light Green \\
4 & Non-vegetation & Yellow \\
5 & Water bodies & Light Blue \\
6 & Cloud/haze/shadow & White \\
\hline
\end{tabular}

Twenty nine reference points from training sites (Fig. 2) were identified with each plot containing only one dominant species. Of the twenty nine plots, twelve plots consisted of Elaeis guineensis, eight plots of Acacia sp. and nine plots of Melaleuca cajuputi (Table 2). A handheld GPS was used to record the geographical coordinates of plant species. Ground truthing results indicated that Elaeis guineensis, Acacia sp. and Melaleuca cajuputi could be identified and discriminated using the SPOT-5 imagery.

To classify and identify the various land cover in this study area, a combination of bands 3, 2 and 1 (NIR, Red and Green) with linear enhancement was selected. The satellite imagery in bands 3, 2 and 1 (NIR, Red and Green) is shown in Fig. 3. Useful information was extracted from this band combination, such as area covered by (i) urban dwelling/structures, (ii) water and river channels, (iii) cloud/haze/shadow and (iv) vegetation. 


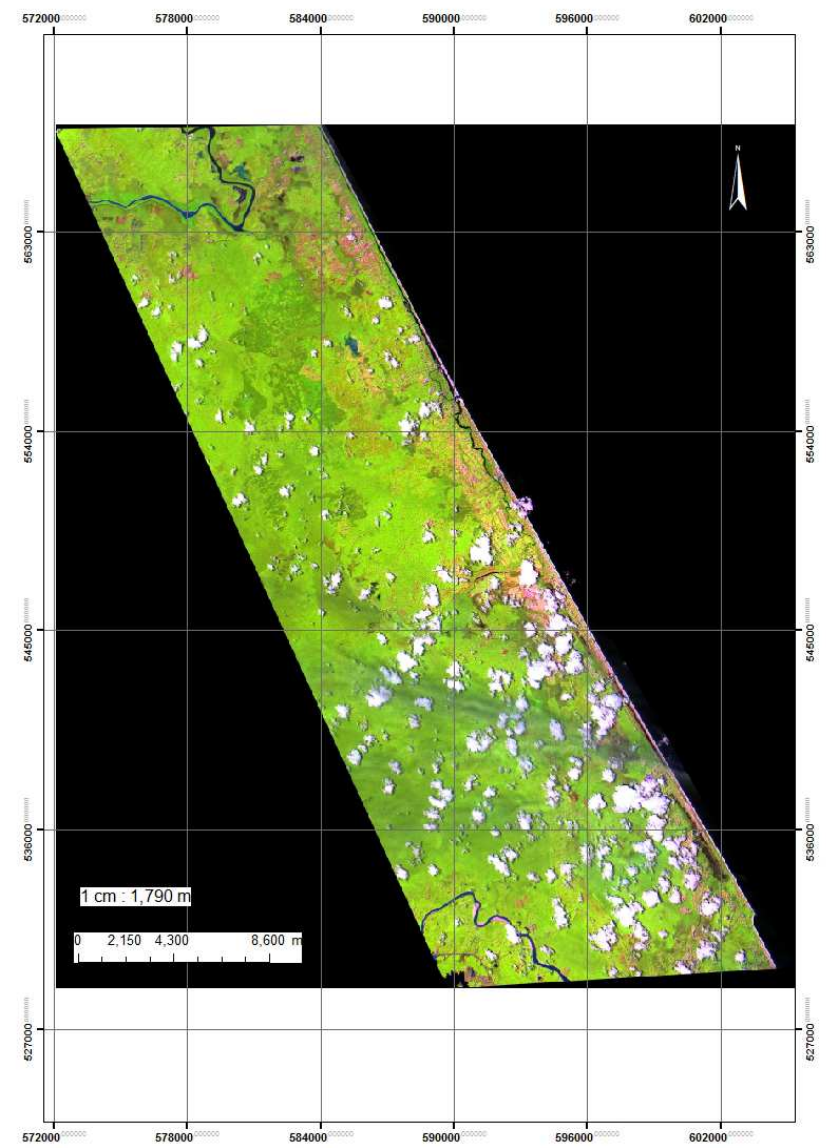

Fig. 3. False color composite (bands 3, 2 and 1) of the SPOT-5 image

Table 4. Statistical estimates of classified attributes on the SPOT-5 image

\begin{tabular}{|c|c|c|c|c|}
\hline Class code & Description & *Pixel & Area (ha) & Percent $(\%)$ \\
\hline 1 & Elaeis guineensis (Oil palm) & 1974511 & 19745.1 & 44.9 \\
\hline 2 & Acacia sp. (Acacia) & 1137775 & 11377.8 & 25.9 \\
\hline 3 & Melaleuca cajuputi (Gelam) & 239884 & 2398.8 & 5.5 \\
\hline 4 & Water bodies & 97349 & 973.5 & 2.2 \\
\hline 5 & Non-vegetation & 464718 & 4647.2 & 10.6 \\
\hline \multirow[t]{2}{*}{6} & Cloud/haze/shadow & 483049 & 4830.5 & 11.0 \\
\hline & TOTAL & 4397287 & 43972.9 & 100.0 \\
\hline
\end{tabular}

$*$ Pixel size $=10 \times 10 \mathrm{~m}$

Supervised classification and delineation of the study area were based on the name assigned to classes according to identification done by ground truthing, visual interpretation and the homogeneous signatures represented by the classes. A Maximum Likelihood Classification (MLC) algorithm was applied on the ROI demarcated on the SPOT-5 imagery. Six different classes, three of which represent the major land cover types, were classified and mapped (Table 3). These six classes were selected because they can be readily interpreted. Figure $\mathbf{4}$ shows the output from the supervised classification, while Table 4 illustrates the statistical fit of the supervised classification. The distribution of the classes is illustrated in Fig. 5. Results show that Elaeis guineensis was the most dominant species in the study area at 19745.1 ha (44.9\%), followed by Acacia sp. at 11377.8 ha (25.9\%) and Melaleuca cajuputi at 2398.8 ha (5.5\%). 
Izzat F. Ibrahim et al. / American Journal of Agricultural and Biological Sciences 7 (4) (2012) 396-406

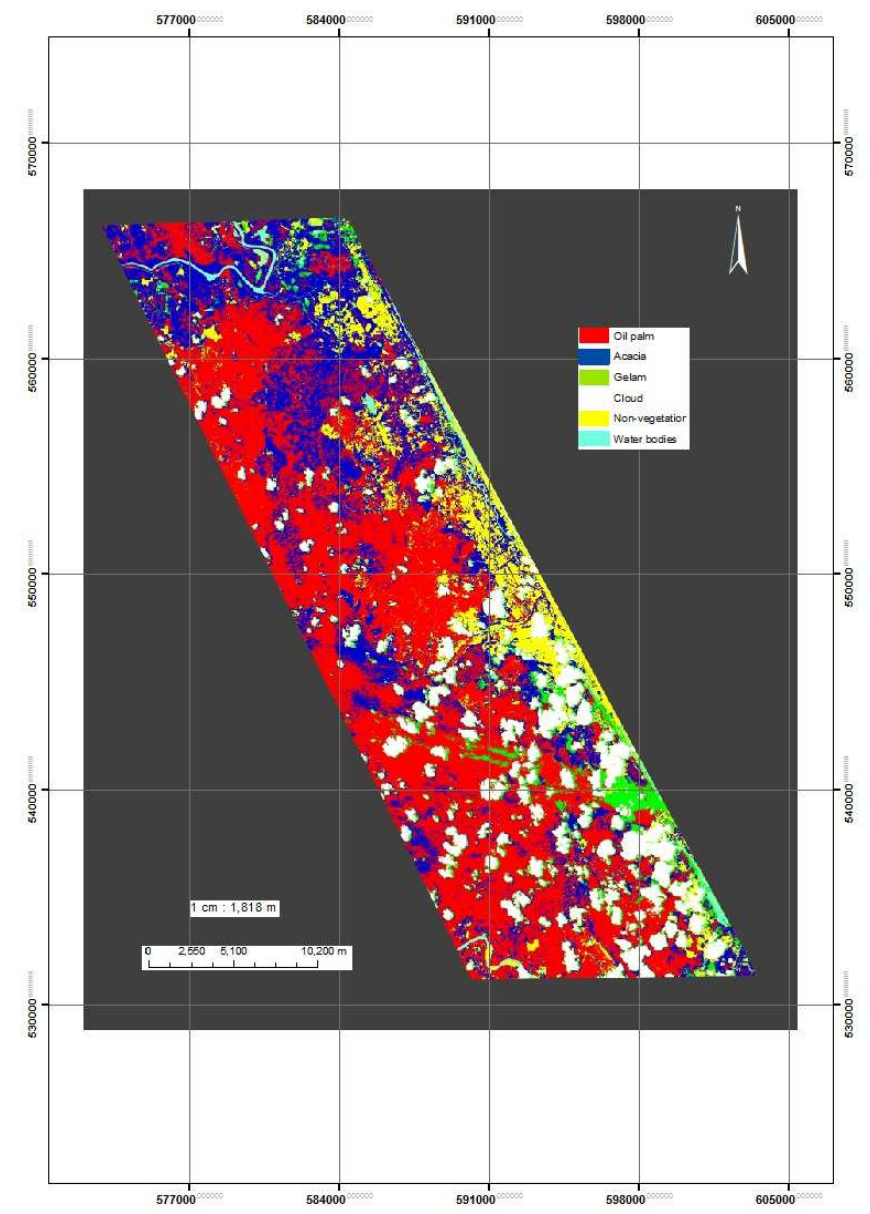

Fig. 4. Classified (using MLC algorithm) SPOT-5 image

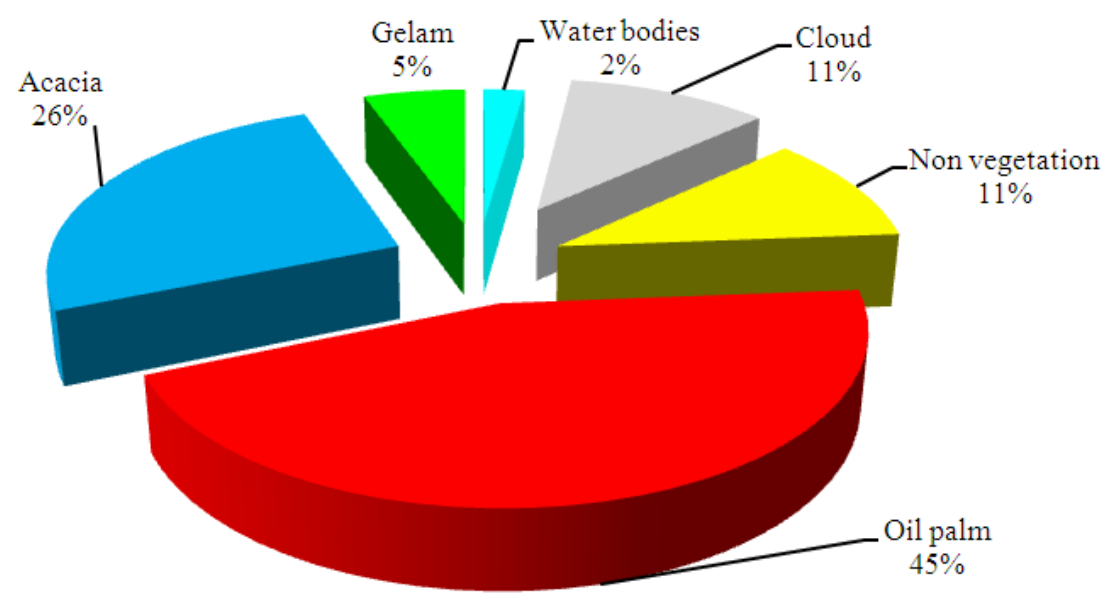

Fig. 5. Percent MLC allocation within the SPOT-5 image 
Izzat F. Ibrahim et al. / American Journal of Agricultural and Biological Sciences 7 (4) (2012) 396-406

Table 5. Classification accuracy of the SPOT-5 image

\begin{tabular}{|c|c|c|c|c|c|}
\hline Class code & Product accuracy ${ }^{1}(\%)$ & User accuracy $^{2}(\%)$ & Omission & Overall accuracy & Kappa coefficient \\
\hline Elaeis guineensis (Oil palm) & 90.2 & 75.8 & 9.8 & & \\
\hline Acacia sp. (Acacia) & 67.2 & 27.6 & 32.8 & & \\
\hline Melaleuca cajuputi (Gelam) & 80.2 & 32.9 & 19.8 & & \\
\hline Non-vegetation & 84.5 & 40.8 & 15.5 & $91.50 \%$ & 0.8 \\
\hline Water bodies & 92.0 & 84.2 & 8.0 & & \\
\hline Cloud/haze/shadow & 92.0 & 99.8 & 8.0 & & \\
\hline
\end{tabular}

${ }^{1}$ Product Accuracy: Percentage of the time a particular land cover type on the ground was identified as the correct land cover type on the map ${ }^{2}$ User Accuracy: Percentage of the time a particular land cover type on the map corresponds to the land cover type on the ground

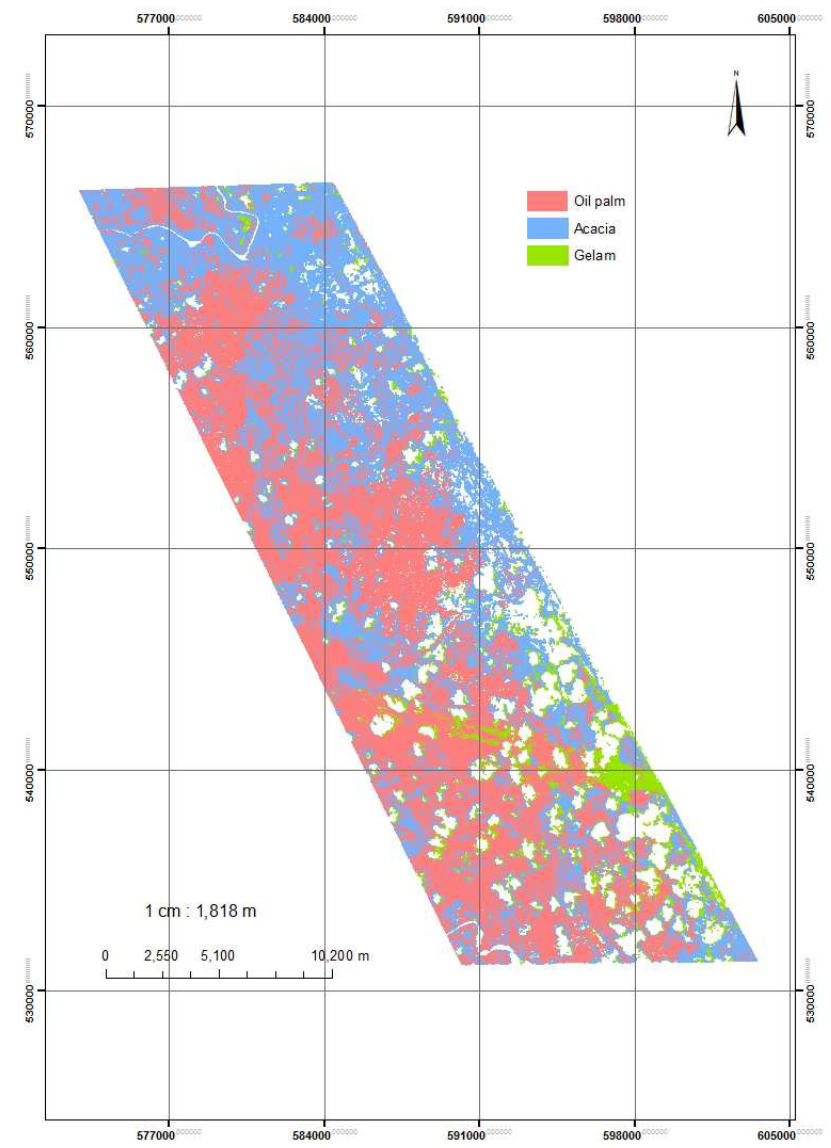

Fig. 6. Vector map illustrating the distribution of Elaeis guineensis, Melaleuca cajuputi and Acacia sp. in the study area

The confusion matrix is given in Table 5. The classified SPOT-5 imagery shows that the product accuracy ranges from $67.2 \%$ for Acacia sp. to $92.0 \%$ for cloud/haze/shadows. The overall accuracy was about 91.5\%. Cloud/haze/shadows showed a very good accuracy (nearly $100 \%$ ). The highest user accuracy was obtained for cloud/haze/shadow (92.0\%). The lowest user accuracy was obtained for Acacia sp. (67.2\%).
The image classification was compared with the Marang district map (1:50000 scale) to confirm that the MLC output was reliable in predicting the distribution of Elaeis guineensis, Melaleuca cajuputi and Acacia sp. As the results showed an accuracy of more than $50 \%$, the next procedure was performed on the SPOT-5 imagery. The filtered classified image, which was in a raster form, was converted into a vector layer (Fig. 6). 


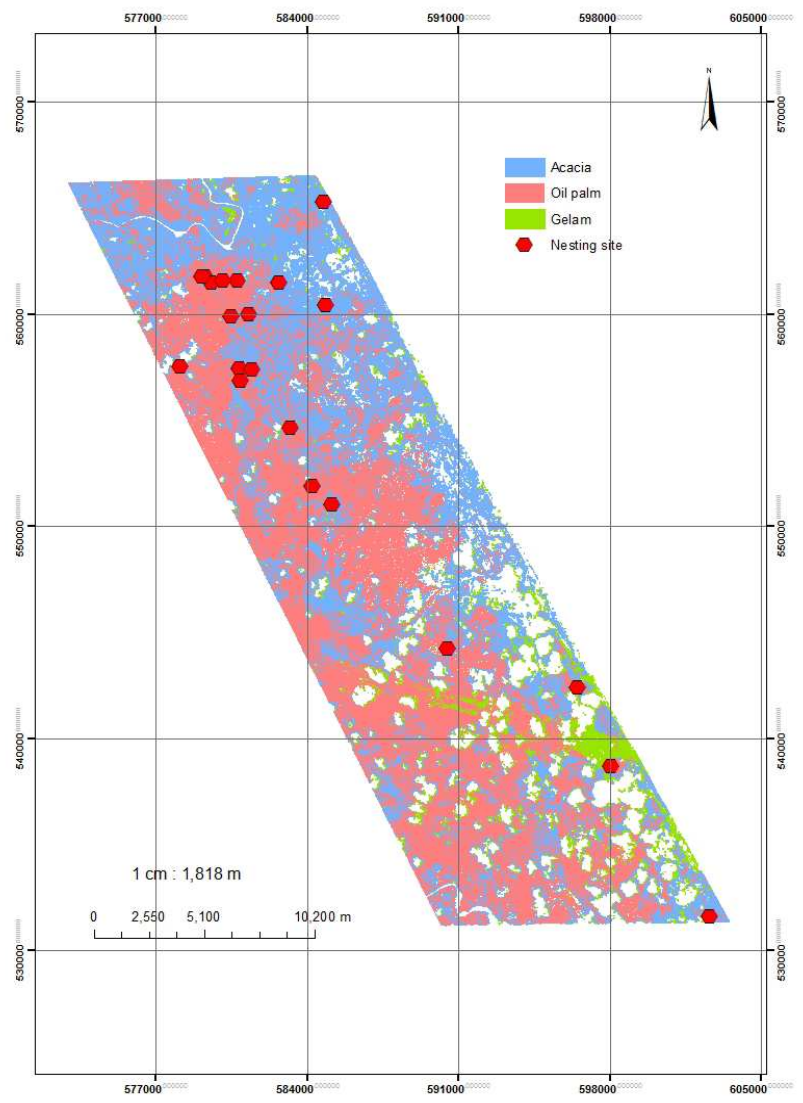

Fig. 7. Distribution of Apis dorsata nesting site within the study area

Table 6. Location of Apis dorsata nesting sites

\begin{tabular}{llll}
\hline Count & Coordinate $\mathrm{x}$ & Coordinat y & Nesting site \\
\hline 1 & 584774.44 & 565273.71 & Forest tree \\
2 & 596541.1 & 542377.23 & Forest tree \\
3 & 598095.04 & 538734.38 & Acacia sp. \\
4 & 602672.85 & 531591.67 & Forest tree \\
5 & 590518.66 & 544266.58 & Elaeis guineensis \\
6 & 585129.4 & 551005.42 & Melaleuca cajuputi \\
7 & 58268.933 & 551911.18 & Forest tree \\
8 & 583227.31 & 554673.74 & Hevea brasiliensis \\
9 & 584881.91 & 560412.24 & Acacia sp. \\
10 & 582684.74 & 561520.37 & Forest tree \\
11 & 578105.25 & 557590.28 & Forest tree \\
12 & 580867.81 & 557499.7 & Melaleuca cajuputi \\
13 & 580822.53 & 556865.67 & Melaleuca cajuputi \\
14 & 581411.27 & 557409.13 & Melaleuca cajuputi \\
15 & 580505.51 & 559945.25 & Forest tree \\
16 & 581275.41 & 560035.82 & Forest tree \\
17 & 580822.53 & 561575.61 & Forest tree \\
18 & 579135.97 & 561764.17 & Forest tree \\
19 & 579281.06 & 561748.05 & Forest tree \\
20 & 579563.17 & 561490.12 & Forest tree \\
21 & 580103.21 & 561554.6 & Forest tree \\
\hline
\end{tabular}

From Fig. 6, it is observed that Elaeis guineensis is widely distributed in the study area. This species is located mostly in the west, northwest and southwest parts of the study area. Acacia sp. is found to be scattered, mostly in the northeast and southeast parts of the study area while Melaleuca cajuputi is found in small pockets around the southeast part of the study area.

Twenty one points were geo-referenced as Apis dorsata nesting sites in the study area (Table 6). All geo-coordinate positions were converted and transferred as an attribute layer onto the map (Fig. 7). The foraging range of Apis dorsata for nesting was configured at 1000 m (Fig. 8). The foraging radius of Apis dorsata and distribution of selected honeybee plants are given in Table 7. Results show that Elaeis guineensis dominated as the most foraged source (sixteen out of twenty one) with a percentage distribution ranging from 76.4-99.2\%. Acacia sp. dominated in four out of twenty one with a percentage distribution ranging from 59.4-96.9\%. Melaleuca cajuputi (Gelam) dominated in one out of twenty one with a percentage distribution of $73.4 \%$. 
Izzat F. Ibrahim et al. / American Journal of Agricultural and Biological Sciences 7 (4) (2012) 396-406

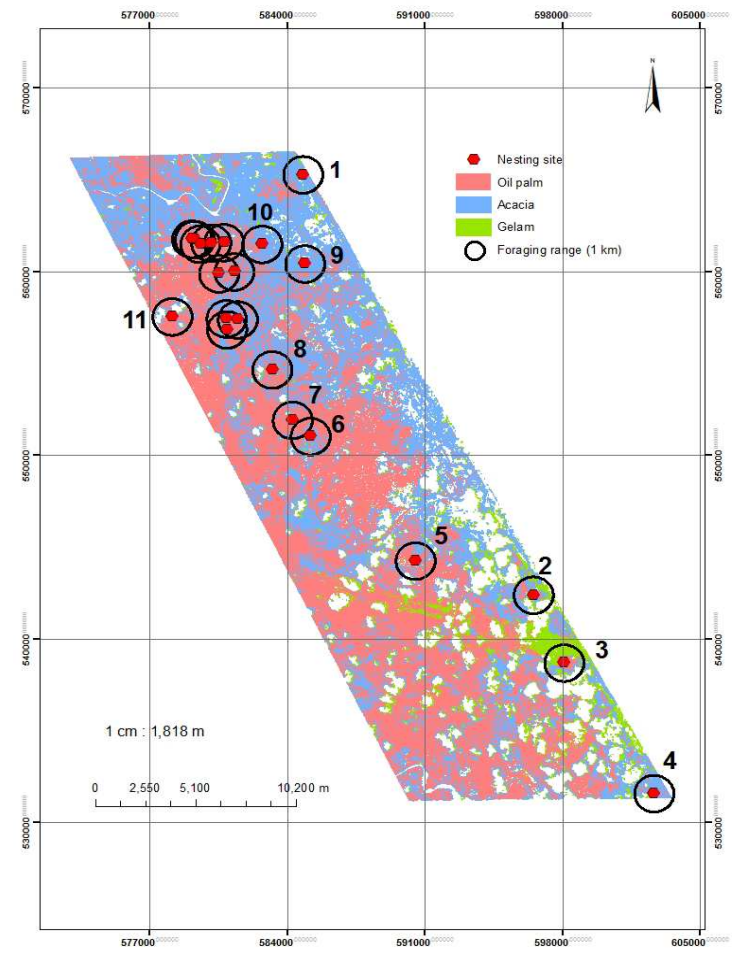

Fig. 8. Foraging radius of Apis dorsata for nesting

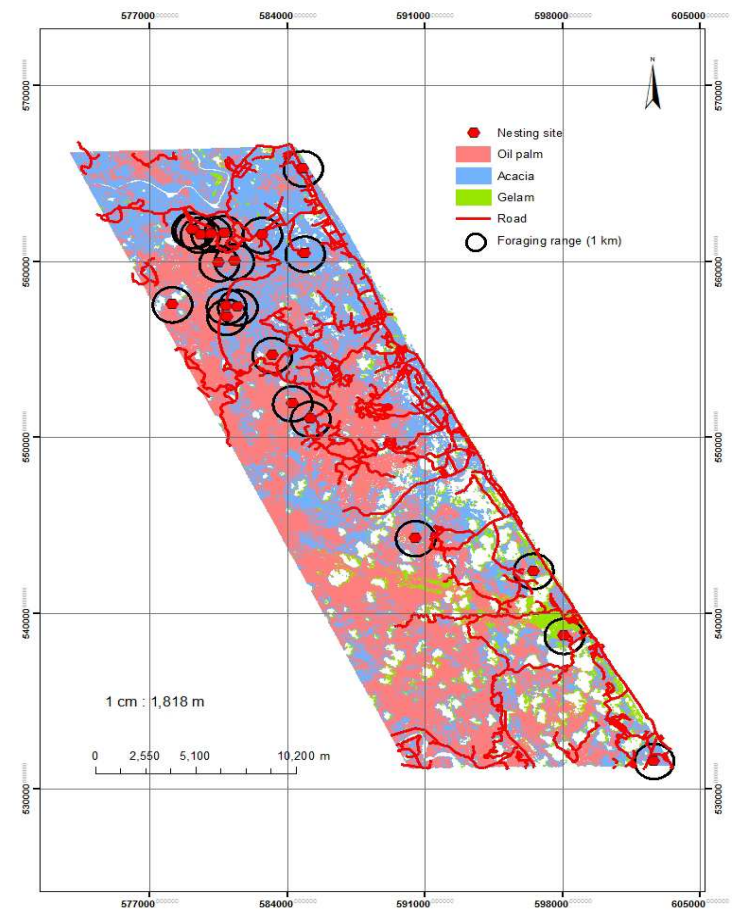

Fig. 9. Honey hunting map indicating road network and nesting sites 


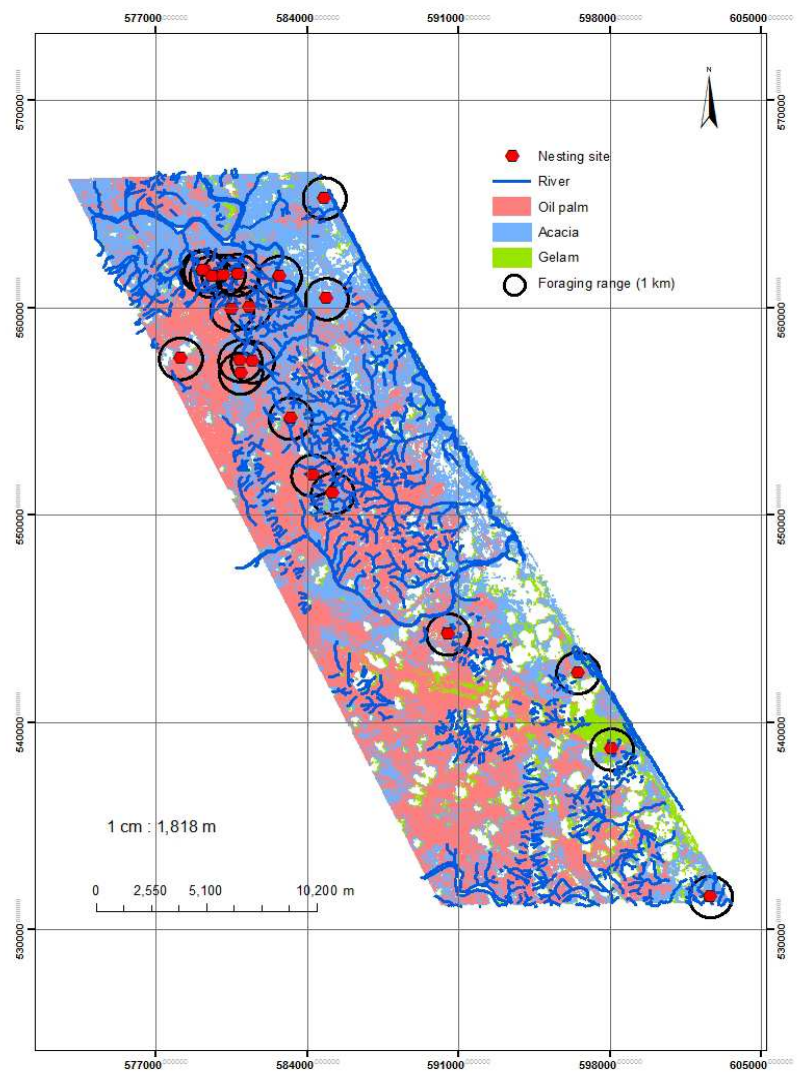

Fig. 10. Honey hunting map indicating river network and nesting sites

Table 7. Foraging radius of Apis dorsata and distribution of selected honeybee plants

\begin{tabular}{lccc}
\hline Foraging radius (count) & \% Oil palm & \% Acacia & \% Gelam \\
\hline 1 & 2.3 & 96.8 & 0.9 \\
2 & 15.7 & 59.4 & 24.9 \\
3 & 15.4 & 11.2 & 73.4 \\
4 & 12.9 & 69.6 & 17.5 \\
5 & 98.9 & 1.0 & 0.1 \\
6 & 99.2 & 0.7 & 0.1 \\
7 & 98.8 & 1.2 & 0.0 \\
8 & 76.8 & 23.2 & 0.0 \\
9 & 3.0 & 96.9 & 0.1 \\
10 & 76.9 & 23.0 & 0.1 \\
11 & 99.7 & 0.3 & 0.0 \\
12 & 76.5 & 23.5 & 0.0 \\
13 & 76.4 & 23.6 & 0.0 \\
14 & 76.5 & 23.5 & 0.0 \\
15 & 76.9 & 23.1 & 0.0 \\
16 & 77.0 & 23.0 & 0.0 \\
17 & 76.9 & 23.1 & 0.0 \\
18 & 77.0 & 23.0 & 0.0 \\
19 & 77.0 & 23.0 & 0.0 \\
20 & 77.0 & 23.0 & 0.0 \\
21 & 77.0 & 23.0 & 0.0 \\
\hline
\end{tabular}

Clearly, Elaeis guineensis covered most of the area that were within the foraging range of Apis dorsata. However, in areas where Elaeis guineensis distribution was low, Acacia sp. or Melaleuca cajuputi were the dominant plants.

Road and river networks in the study area were derived from digital cartographic maps and were overlain on ArcGIS 9.3.1 to depict the honey hunting map as a GIS interface. This map indicates possible locations of Apis dorsata nesting sites for honey hunting in the study area. The map with the road network (Fig. 9) and the map with the river network (Fig. 10) serve as a useful guide for honey hunters to strategically pursue locations that comply with the basic nesting requirements of Apis dorsata, such as Elaeis guineensis and Acacia sp. as a source of pollen and Melaleuca cajuputi as a source of nectar.

\section{DISCUSSION}

The highest user accuracy was obtained for cloud/haze/shadow $(92.0 \%)$. This is expected as this 
attribute class could be easily detected via image characteristics, which are clearly distinguishable from the typical land-based attributes. The vegetation-based attributes resulted in some confusion due to similarity in texture or tone. Low accuracy for Acacia sp. (67.2\%) was probably due to lack of ground truthing points in the entire study area. Also, these ground truthing points were not well scattered within the study area.

Elaeis guineensis was widely distributed in the study area. Most of these locations are under the governance of Federal Land Development Authority (FELDA). In the FELDA scheme, Elaeis guineensis is planted as the main crop in a large scale. This is probably the reason why Elaeis guineensis was found to be dominant in the study area. Acacia sp. was found to be scattered. This species grows well on wasteland, secondary forest and sideways under wild conditions. Villagers use this species as raw material for housing, which explains why its distribution is not as dominant as Elaeis guineensis. Melaleuca cajuputi was found in small pockets around the southeast part of the study area. Typically, Melaleuca cajuputi grows well in swampland. The southeastern part of the study area is rich in swampland and makes it suitable for Melaleuca cajuputi growth. At present, the acreage of swampland is dwindling due to physical development. As a result, Melaleuca cajuputi is becoming scant.

It is clear that the majority of Apis dorsata nesting sites were located on forest trees. This implies that Apis dorsata construct their nest on forest tree branches for nesting support. The preference of Apis dorsata toward forest trees is possibly related to the tree architecture of the forest species.

\section{CONCLUSION}

The SPOT-5 multispectral imagery and analysis served as a useful tool for developing the inventory of Elaeis guineensis within the study area. The SPOT-5 image classification in the study area revealed the following areal distribution: Elaeis guineensis at 19745.1 ha (44.9\%), Acacia sp. at 11377.8 ha (25.9\%), Melaleuca cajuputi at 2398.8 ha $(5.5 \%)$, water bodies at 973.5 ha $(2.2 \%)$, non-vegetation at 4647.2 ha $(10.6 \%)$ and cloud/haze/shadow at 4830.5 ha $(11.0 \%)$. The confusion matrix revealed a classification accuracy ranging from $67.2 \%$ for Acacia sp. to $92.0 \%$ for cloud/haze/shadow. The overall accuracy and Kappa coefficient for the MLC classification were $91.5 \%$ and 0.8 , respectively.

The GIS-RS map, produced by overlaying several data layers, showed that almost all of the Apis dorsata nesting sites were located in the Elaeis guineensis area. This study clearly demonstrates that Apis dorsata prefers to build its nest in close proximity to the pollen source.

\section{ACKNOWLEDGEMENT}

This study was funded in part by the Research University Grant Scheme (RUGS) of Universiti Putra Malaysia and the Royal Foundation of Sultan Mizan, Malaysia.

\section{REFERENCES}

Hudson, W.D. and C.W. Ramm, 1987. Correct formulation of the Kappa coefficient of agreement. Photogrammetric Eng. Remote Sens., 53: 421-422.

Jo, M.H., J.B. Kim and S.R. Baek, 2001. Selection technique for honey plant complex area using Landsat image and GIS. Proceeding of the 22nd Asian Conference on Remote Sensing, Nov. 5-9, Singapore, pp: 1-6.

Mezquida, D.A. and J.L. Martinez, 2009. Short communication. Platform for bee-hives monitoring based on sound analysis. A perpetual warehouse for swarm's daily activity. Spanish J. Agric. Res., 7: 824-828.

Mohti, A., 2006. Mapping the central matang mangrove forest reserve, perak, using remote sensing and geographic information system. MS.c. Thesis, Universiti Putra Malaysia.

Saberioon, M.M., M. Mardan, L. Nordin, M.S. Alias and A. Gholizaeh, 2009. Fusion SPOT-5 and Radarsat-1 images for mapping major bee plants in Marang District, Malaysia. Eur. J. Sci. Res., 38: 465-473.

Sulzer, W., G. Kastberger, M. Muick, M. Hirschmugl and E. Huettinger, 2010. Multitemporal crop and land cover analysis in Chitwan (Nepal) by means of remote sensing. Proceedings of the 10th International Symposium on High Mountain Remote Sensing Cartography, (HMRSC' 10), Grazer Schriften der Geographie und Raumforschung, pp: 73-82.

Toan, T.L., S. Quegan, I. Woodward, M. Lomas and N. Delbart et al., 2004. Relating radar remote sensing of biomass to modelling of forest carbon budgets. Climate Change, 67: 379-402. 